\title{
Editorial
}

HORMONE

RESEARCH IN

Horm Res Paediatr 2019;92:345-346

DOI: $10.1159 / 000507703$

PAEDIATRICS

\section{Pediatric Endocrinology in the Time of the COVID-19 Pandemic}

\author{
Stefano Cianfarani ${ }^{a, b}$ \\ aDipartimento Pediatrico Universitario Ospedaliero "Bambino Gesù" Children's Hospital - Tor Vergata University, \\ Rome, Italy; ${ }^{b}$ Department of Women's and Children's Health, Karolinska Institutet and University Hospital, \\ Stockholm, Sweden
}

\section{Getting Back to Our Pediatric Roots}

The current pandemic of coronavirus disease 2019 (COVID-19) is severely affecting health systems worldwide and changing both our lifestyles and our work. In these difficult times, the priority of all health care professionals is to take care of the infected sick. The pediatric endocrinology (PedEndo) community is currently actively committed to the daily care of children suspected of having COVID-19 infection or being affected by it, in addition to those with endocrine diseases. In contrast to findings in the majority of adults, children with COVID-19 have mild clinical manifestations, and are mostly asymptomatic [1-3]. Nevertheless, pediatric endocrinologists worldwide, especially the younger ones, have been forced by current events to divert the focus of their clinical practice as well as scientific interest and reading to general pediatrics and even to infectious diseases and epidemiology. This sudden and unexpected challenge has, ultimately, urged pediatric subspecialists to rediscover the original appeal and importance of general pediatrics. My mentor, Prof. Brunetto Boscherini, used to say that only a skilled pediatrician may become a skilled pediatric endocrinologist. Therefore, this awful epidemic may ulti- mately lead to a significant improvement in training and expertise as well as the global view of the sick child in the PedEndo community.

\section{PedEndo Research during the COVID-19 Epidemic}

The primary scientific effect of the COVID-19 pandemic is to boost research in the fields of virology, immunology, and epidemiology. However, other disciplines, including PedEndo, can also contribute to a better knowledge of pathogenesis and consequences of COVID-19. I provide a few examples here of the potential role of PedEndo in investigating the endocrine implications of SARS-CoV-2 infection.

To enter host cells, SARS-CoV-2 (the virus responsible for the COVID-19 pandemic) and SARS-CoV-1 (responsible for the SARS epidemic in 2002) need to bind to cell surface receptor angiotensin-converting enzyme 2 (ACE2) [4]. ACE2 degrades angiotensin II to angiotensin-(1-7) and participates in the hydrolysis of other peptides including angiotensin I. ACE2 is expressed in many human tissues, including the lungs, heart, and kidneys. It has been postulated that inhibitors of the renin-angioten-

\section{KARGER}

๑) 2020 S. Karger AG, Basel

karger@karger.com

www.karger.com/hrp
Prof. Stefano Cianfarani

Dipartimento Pediatrico Universitario Ospedaliero

“Bambino Gesù” Children's Hospital - Tor Vergata University

Piazza S. Onofrio 4, IT-00165 Rome (Italy)

stefano.cianfarani@uniroma2.it and stefano.cianfarani@opbg.net 
sin-aldosterone system, commonly used as antihypertensive drugs, may increase the expression of ACE2, ultimately facilitating the viral invasion. However, data in favor of this hypothesis are largely insufficient and experimental and clinical research is warranted [5].

The entry of SARS-CoV-2 into the host cells depends not only on ACE2 but requires a more complex mechanism. In fact, the spike (S) protein of the coronavirus surface plays a key role in viral entry into the target cells. $S$ protein must first be cleaved by a specific protease to be able to attach to the cell surface. The main protease involved in $S$ protein priming is transmembrane protease serine 2 (TMPRSS2), which thus represents a critical host cell factor for the invasion and spread of the virus $[6,7]$. It is noteworthy that TMPRSS2 expression is upregulated by androgens [8] and modulated by specific microRNAs [9]. These findings suggest that the endocrine system may play a role in viral entry into target cells.

From the clinical perspective, a follow-up study was conducted in a cohort of 61 adult survivors of the SARS outbreak in 2002 to investigate the potential long-term endocrine impact of the disease [10]. Twenty-four patients (39\%) showed central hypocortisolism which resolved within a year in most of them, and three showed central hypothyroidism. The authors speculated that the coronavirus infection could have caused a reversible hypophysitis. No similar follow-up studies have been conducted on children.

Finally, the impact of coronavirus infection in adult diabetic patients is well established, with the evidence showing a link between type 2 diabetes and disease severity $[11,12]$. To date, no study has reported data on the interaction between SARS-CoV-2 infection and type 1 diabetes in children.

\section{PedEndo Is Not Locked Down}

PedEndo may appear as a minor discipline at a time of worldwide emergency like what we are currently experiencing, but the PedEndo community is adapting to this crisis. We are not only sticking to the primary duty of taking care of children with endocrine diseases, but also contributing substantially to the daily care of children with COVID-19 and general pediatric diseases. Furthermore, pediatric endocrinologists may concur, with their research, in improving the knowledge of SARS-CoV-2 infection dynamics from the viral entry into cells to longterm sequelae.

Finally, though many important international conferences have been cancelled or postponed, we are absolutely committed to stay up to date on the latest research in endocrinology by means of journals, books, videos, and Web-meetings.

\section{Disclosure Statement}

The author has no conflict of interests.

\section{References}

1 Qiu H, Wu J, Hong L, Luo Y, Song Q, Chen D. Clinical and epidemiological features of 36 children with coronavirus disease 2019 (COVID-19) in Zhejiang, China: an observational cohort study. Lancet Infect Dis. 2020 Mar;S1473-3099(20)30198-5.

$2 \mathrm{Wu} \mathrm{Z}, \mathrm{McGoogan}$ JM. Characteristics of and Important Lessons from the Coronavirus Disease 2019 (COVID-19) Outbreak in China: Summary of a Report of 72314 Cases from the Chinese Center for Disease Control and Prevention. JAMA. 2020 Feb. DOI: 10.1001/ jama.2020.2648. E-pub ahead of print.

3 Liu W, Zhang Q, Chen J, Xiang R, Song H, Shu S, et al. Detection of Covid-19 in Children in Early January 2020 in Wuhan, China. N Engl J Med. 2020 Apr;382(14):1370-1.

4 Letko M, Marzi A, Munster V. Functional assessment of cell entry and receptor usage for SARS-CoV-2 and other lineage $B$ betacoronaviruses. Nat Microbiol. 2020 Apr;5(4):562-9.
5 Vaduganathan M, Vardeny O, Michel T, McMurray JJ, Pfeffer MA, Solomon SD. ReninAngiotensin-Aldosterone System Inhibitors in Patients with Covid-19. N Engl J Med. 2020 Mar;NEJMsr2005760.

6 Hoffmann M, Kleine-Weber H, Schroeder S, Krüger N, Herrler T, Erichsen S, et al. SARSCoV-2 Cell Entry Depends on ACE2 and TMPRSS2 and Is Blocked by a Clinically Proven Protease Inhibitor. Cell. 2020 Mar;S0092-8674(20)30229-4.

7 Matsuyama S, Nao N, Shirato K, Kawase M, Saito S, Takayama I, et al. Enhanced isolation of SARS-CoV-2 by TMPRSS2-expressing cells. Proc Natl Acad Sci USA. 2020 Mar; 117(13):7001-3.

8 Lin B, Ferguson C, White JT, Wang S, Vessella R, True LD, et al. Prostate-localized and androgen-regulated expression of the membrane-bound serine protease TMPRSS2. Cancer Res. 1999 Sep;59(17):4180-4.
9 Zoni E, Karkampouna S, Thalmann GN, Kruithof-de Julio M, Spahn M. Emerging aspects of microRNA interaction with TMPRSS2-ERG and endocrine therapy. Mol Cell Endocrinol. 2018 Feb;462 Pt A:9-16.

10 Leow MK, Kwek DS, Ng AW, Ong KC, Kaw GJ, Lee LS. Hypocortisolism in survivors of severe acute respiratory syndrome (SARS). Clin Endocrinol (Oxf). 2005 Aug;63(2):197202.

11 Badawi A, Ryoo SG. Prevalence of Diabetes in the 2009 Influenza A (H1N1) and the Middle East Respiratory Syndrome Coronavirus: A Systematic Review and Meta-Analysis. J Public Health Res. 2016 Dec;5(3):733.

12 Yang J, Zheng Y, Gou X, Pu K, Chen Z, Guo $\mathrm{Q}$, et al. Prevalence of comorbidities in the novel Wuhan coronavirus (COVID-19) infection: a systematic review and meta-analysis. Int J Infect Dis. 2020 Mar;S1201-9712 (20)30136-3. 